\title{
Lipopolysaccharide-induced apoptosis in a murine intestinal endocrine cell line by modulation of Bcl-2, Bax and caspase-3
}

\author{
LEI LEI ${ }^{*}$, JIAO WANG $^{*}$, ZHEN ZHANG, HUA ZHANG, HONG CHEN and DEHONG CAI \\ Department of Endocrinology, Zhujiang Hospital, Southern Medical University, Guangzhou, Guangdong 510280, P.R. China
}

Received July 23, 2013; Accepted October 15, 2013

DOI: $10.3892 / \mathrm{mmr} .2013 .1744$

\begin{abstract}
Numerous studies have focused on how to modulate the secretion of glucagon-like peptide 1 (GLP-1) due to its marked anti-diabetic function. However, few studies have investigated the apoptosis of enteroendocrine L cells, which secrete GLP-1. The aim of this study was to determine whether lipopolysaccharide (LPS), a gut bacterial product, is capable of inducing apoptosis in the intestinal endocrine cell line STC-1. We found that LPS is capable of reducing the viability of STC-1 cells in a concentration-dependent manner. annexin V/propidium iodide (PI) double staining detected by fluorescence microscopy and flow cytometry revealed a strong apoptosis-inducing ability for LPS in STC-1 cells. Furthermore, western blotting revealed that exposure to LPS significantly decreased the expression of $\mathrm{Bcl}-2$ and increased the expression of Bax and caspase-3. In conclusion, LPS induced the apoptosis of STC-1 cells in a dose-dependent manner, which may be responsible for the reduced secretion of GLP-1 in diabetes.
\end{abstract}

\section{Introduction}

Diabetes is associated with a number of chronic conditions, including inflammation, insulin resistance, hepatic steatosis and cardiovascular disease. Recent studies have revealed that gut microbes may play an important role in diabetes and metabolic diseases. These microbes may affect homeostasis as environmental factors. Over the past few years, new evidence has demonstrated that the increasing prevalence of type 2 diabetes and obesity may be partly attributed to disorders of the host gut microbiota. Larsen et al (1) suggested that type 2 diabetes in humans is associated with changes in the composition of the intestinal microbiota. The authors of that study

Correspondence to: Professor Dehong Cai, Department of Endocrinology, Zhujiang Hospital, Southern Medical University, 253 Industrial Avenue, Guangzhou, Guangdong 510280, P.R. China E-mail: cai_de_hong-zzyy@hotmail.com

\section{*Contributed equally}

Key words: lipopolysaccharide, apoptosis, glucagon-like peptide 1, enteroendocrine L cells found a reduction in the levels of Firmicutes and an increase in the levels of Bacteroidetes in diabetic patients compared with their non-diabetic counterparts.

Glucagon-like peptide 1 (GLP-1) is an incretin hormone secreted by enteroendocrine $\mathrm{L}$ cells that are scattered throughout the gastrointestinal mucosa. GLP-1 is crucial in the treatment of diabetes as it stimulates insulin, suppresses the secretion of glucagon, inhibits gastric emptying and reduces appetite and food intake (2). The secretion of GLP-1 has been shown to be markedly reduced in type 2 diabetes $(3,4)$. However, the mechanism underlying this change is poorly understood. We propose that damaged enteroendocrine L cells are responsible for this incretin defect.

Cani and Delzenne (5) found that the bacteria-related factor lipopolysaccharide (LPS) may be responsible for the development of diabetes. Subsequently, Creely et al (6) reinforced the hypothesis that LPS may act as a gut microbiota-related factor in the development of type 2 diabetes in humans. LPS is a complex glycoprotein constituent of the outer cell wall of gram-negative bacteria. It is continuously released from the surface of replicating and dying gram-negative bacteria, such as Bacteroidetes, into the gastrointestinal tract. LPS levels increase significantly in the gut of diabetic patients, which makes them interact constantly with the intestinal epithelium. Enteroendocrine L cells, which are scattered among the intestinal epithelium, are constantly exposed to high concentrations of LPS in patients with type 2 diabetes. This interaction may induce apoptosis in enteroendocrine L cells.

Increasing attention has been focused on how to modulate the secretion of GLP-1 by enteroendocrine L cells. However, few studies have focused on apoptosis of enteroendocrine $\mathrm{L}$ cells potentially being a mechanism underlying the decreased secretion of GLP-1 in patients with type 2 diabetes. In this study, we investigated whether LPS was capable of inducing apoptosis in the intestinal endocrine cell line STC-1. This cell line has been established as a good cellular model for the study of GLP-1 secretion and transcription (7-9). The results suggest that LPS induces apoptosis in STC-1 cells by regulating the expression of three key proteins, caspase-3, Bax and Bcl-2, which are critical for apoptosis.

\section{Materials and methods}

Cell cultures. STC-1 cells were obtained from the Guangzhou Jennio Biotech Co., Ltd. (Guangzhou China). Cells were 
cultured in DMEM (Hyclone, Logan, UT, USA) supplemented with $2.5 \%$ (vol/vol) fetal bovine serum (Gibco, Carlsbad, CA, USA), $10 \%$ (vol/vol) horse serum (Gibco), $100 \mathrm{U} / \mathrm{ml}$ penicillin (Life Technologies, Carlsbad, CA, USA) and $100 \mathrm{U} / \mathrm{ml}$ streptomycin (Life Technologies), and incubated in a humidified atmosphere containing $5 \% \mathrm{CO}_{2}$ at $37^{\circ} \mathrm{C}$. The medium was changed every 2-3 days. When the cells reached $80-90 \%$ confluence, they were trypsinized with $0.25 \%$ trypsin-EDTA (Sigma-Aldrich, St. Louis, MO, USA) and subsequently replated into culture flasks. Each experiment was repeated at least three times $(n \geq 3)$.

Cell viability assay. For the 3-(4,5-dimethylthiazol-2-yl)-2,5diphenyltetrazolium bromide (MTT) assay, $2 \times 10^{4}$ cells/well were seeded in 96 -well plates for $24 \mathrm{~h}$ at $37^{\circ} \mathrm{C}$ and starved for a further $24 \mathrm{~h}$ in serum-free DMEM. Subsequently, the cells were exposed to LPS (Escherichia coli 0111:B4; Sigma-Aldrich) at various concentrations $(0,0.1,0.5,1$ and $10 \mu \mathrm{g} / \mathrm{ml})$ at $100 \mu \mathrm{l} /$ well. Following incubation for $24 \mathrm{~h}, 20 \mu \mathrm{l} /$ well of MTT (Sigma-Aldrich) solution $(5 \mathrm{mg} / \mathrm{ml}$ in PBS) was added and the cells were cultured at $37^{\circ} \mathrm{C}$ for $4 \mathrm{~h}$. Subsequently, the supernatant was discarded carefully. The formazan crystals were dissolved in $100 \mu 1 /$ well of DMSO. The plates were agitated for $5 \mathrm{~min}$, and the absorbance of solubilized formazan was measured at $570 \mathrm{~nm}$ using an automatic microplate reader (Multiskan MK3, Thermo Fisher Scientific Inc., Waltham, MA, USA). Cell survival was expressed as the ratio of the absorbance of treated cells to the untreated cells.

Hoechst 33258 staining. STC-1 cells $\left(1 \times 10^{6}\right.$ cells/well) were exposed to various concentrations of LPS for $24 \mathrm{~h}$. The cells were washed in PBS and stained with Hoechst $33258(5 \mu \mathrm{g} / \mathrm{ml})$ for $5 \mathrm{~min}$ at $37^{\circ} \mathrm{C}$. The stained cells were washed twice in PBS and then observed immediately using a fluorescence microscope (Leica; Wetzlar, Germany). An Ex/Em filter set of BP330-380/LP420 $\mathrm{nm}$ was used, and the images were recorded using a color charge-coupled device camera.

Analysis for annexin V. Cells $\left(2 \times 10^{6}\right)$ were seeded into six-well plates for $24 \mathrm{~h}$ and starved for a further $12 \mathrm{~h}$ in serum-free DMEM. Apoptotic cells were identified based on the translocation of phosphatidylserine from the inner to the outer leaflet of the plasma membrane, measured using an annexin V/propidium iodide (PI) double staining apoptosis detection kit (Life Technologies). Following treatment with or without various concentrations of LPS for 24 or $6 \mathrm{~h}$, the cells were washed three times with PBS and immediately fixed in 4\% paraformaldehyde for 15 min or harvested and washed three times in cold PBS and resuspended in an annexinbinding buffer. Subsequently, the fixed cells were added with annexin V-fluorescein isothiocyanate (FITC) and PI buffer, while the resuspended cells were added to annexin V-FITC and PI directly. The reaction was incubated at room temperature for $15 \mathrm{~min}$ in the dark. Stained cells were analyzed immediately using an Accuri C6 flow cytometer (BD Biosciences; San Jose, California, USA) and a fluorescence microscope (Leica). Fluorescence was detected with an excitation wavelength of $488 \mathrm{~nm}$.

For flow cytometry, the LPS exposure time was reduced to $6 \mathrm{~h}$. This change was due to the fact that flow cytometry

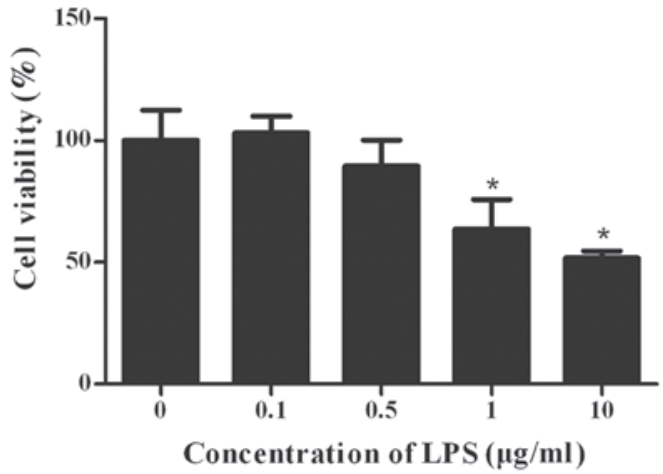

Figure 1. Effects of lipopolysaccharide (LPS) on the viability of STC-1 cells STC-1 cells $\left(2 \times 10^{4}\right.$ cells/well) were incubated with $0,0.1,0.5,1$ and $10 \mu \mathrm{g} / \mathrm{ml}$ LPS for $24 \mathrm{~h}$ and cell viability was determined by 3-(4,5-dimethylthiazol2-yl)-2,5-diphenyltetrazolium bromide (MTT) assay. The values shown are the means \pm SD of three different preparations with quadruplicate experiments. ${ }^{*} \mathrm{P}<0.05$ vs. control.

using annexin $\mathrm{V}$ staining is a more sensitive technique for detecting apoptosis compared with the other techniques used in our study.

Western blotting. In order to examine $\mathrm{Bcl}-2$, Bax and caspase-3 protein levels, cells were grown in culture flasks and treated with LPS as described in a previous section. After washing in ice-cold PBS, cells were lysed in a lysis buffer [50 mM Tris- $\mathrm{HCl}, \mathrm{pH}$ 7.4; $150 \mathrm{mM} \mathrm{NaCl} ; 1 \mathrm{mM}$ phenylmethanesulfonylfluoride (PMSF); 1 mM EDTA; $1 \%$ Triton $\mathrm{X}-100 ; 1 \%$ sodium deoxycholate; and $0.1 \%$ sodium dodecyl sulfate (SDS); Sigma-Aldrich] at $4^{\circ} \mathrm{C}$ for $30 \mathrm{~min}$. Cell lysates were centrifuged for $10 \mathrm{~min}$ at $15,400 \mathrm{rpm}$ at $4^{\circ} \mathrm{C}$, and the supernatants were collected. The protein concentration of the samples was estimated according to the BCA method (10). Subsequently, $50 \mu \mathrm{g}$ of total protein from each sample was separated via $10 \%$ sodium dodecyl sulfate-polyacrylamide gel electrophoresis (SDS-PAGE) and blotted onto nitrocellulose membranes. The membranes were blocked with $2 \%$ non-fat dry milk in PBS containing $0.25 \%$ Tween-20 overnight and incubated with Bcl-2, Bax (Cell Signaling Technology, Beverly, MA, USA) and caspase-3 (Santa Cruz Biotechnology Inc., Santa Cruz, CA, USA) antibodies for $2 \mathrm{~h}$ at room temperature. Following the three washing steps, anti-horseradish peroxidase-conjugated secondary antibodies (Beyotime, Haimen, China) were applied, and the membranes were stained using enhanced chemiluminescence reagents (Beyotime). The autoradiographs were scanned and semiquantitatively quantified.

Statistical analyses. Data were presented as the means \pm SD. Significant differences between groups were evaluated using one-way analysis of variance (ANOVA). $\mathrm{P}<0.05$ was considered to indicate a statistically significant difference.

\section{Results}

LPS affects the viability of STC-1 cells. STC-1 cells were cultured in the absence and presence of varying concentrations of LPS for $24 \mathrm{~h}$. The effects of LPS on cell viability were assessed by MTT assay (Fig. 1). Exposure to increasing concentrations of LPS induced a dose-dependent decrease 
A
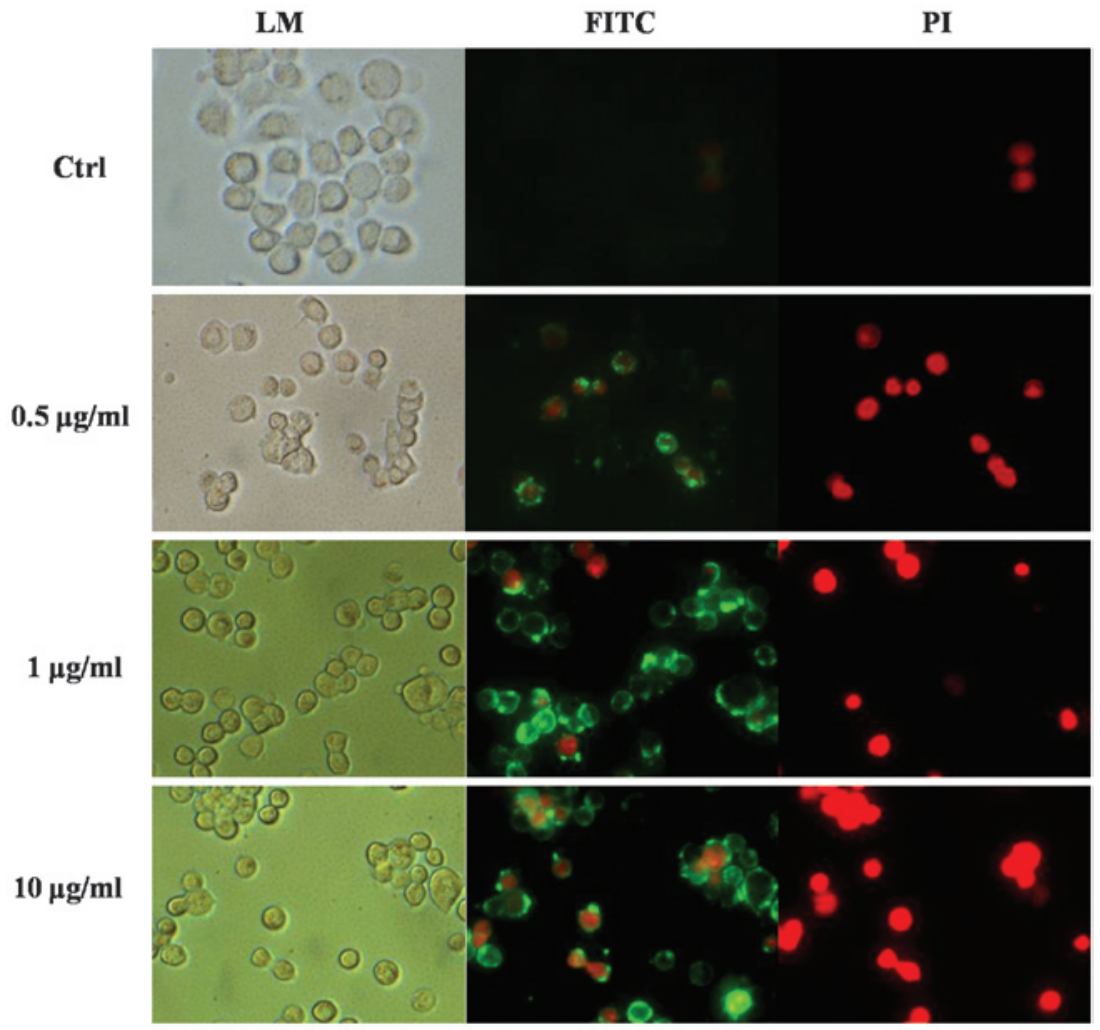

B

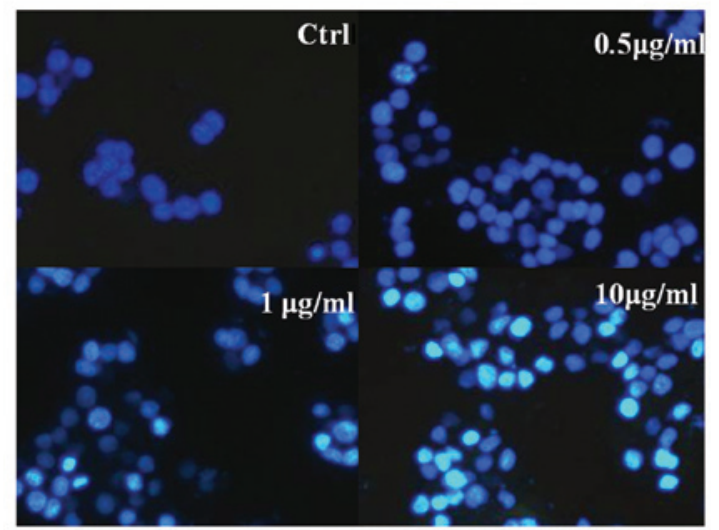

Figure 2. STC-1 cell morphology changes were observed by fluorescence microscopy (magnification, $\mathrm{x} 200$ ) $24 \mathrm{~h}$ after treatment with various concentrations of lipopolysaccharide (LPS). (A) Panels on the left show cells observed by light microscopy (LM), and middle and right panels show annexin V labeled with fluorescein isothiocyanate (FITC) (green fluorescence) and nucleic acid staining with propidium iodide (PI) (red fluorescence), respectively. (B) STC-1 cells were stained with Hoechst 33258. Apoptotic cells were identified by their typical nuclear appearance.

in cell survival. At the highest tested concentration of LPS $(10 \mu \mathrm{g} / \mathrm{ml})$, the survival rate was $52 \pm 3 \%$ when compared with the control group. At $1 \mu \mathrm{g} / \mathrm{ml}$ LPS, cell viability was reduced to $64 \pm 12 \%$. However, no significant growth inhibition was observed when LPS was added at a concentration of $0.1 \mu \mathrm{g} / \mathrm{ml}$ and $0.5 \mu \mathrm{g} / \mathrm{ml}$.

Cell morphology. Following staining with an annexin V/PI apoptosis kit, living cells demonstrated little or no fluorescence, and apoptotic cells exhibited green fluorescence. Necrotic cells exhibited both red and green fluorescence. As shown in Fig. 2A, the cells show weak green fluorescence, and no red fluorescence is found in the control groups. The fluorescence intensity of the $0.5 \mu \mathrm{g} / \mathrm{ml}$ groups was similar to that of the control group. However, the number of cells with strongly green fluorescence increased with the increasing concentrations of LPS (1-10 $\mu \mathrm{g} / \mathrm{ml})$. This indicates that apoptosis was more prevalent at high concentrations of LPS.

The results of Hoechst 33258 staining were consistent with the findings observed in a previous section. As shown in Fig. 2B, normal STC-1 cells exhibited weak fluorescence. Following LPS treatment, the cells demonstrated a brighter fluorescence, and typical apoptotic characteristics, such as nuclear condensation, were observed in cells treated with 1 or $10 \mu \mathrm{g} / \mathrm{ml}$ LPS.

Flow cytometry. The lower right quadrant of each plot indicates the percentage of early apoptotic cells that are only annexin V-FITC-positive. The upper right quadrant shows late apoptotic cells or necrotic cells with positive staining for annexin V-FITC and PI. In order to avoid interference from necrotic cells, the apoptotic cells in this portion of the 
A

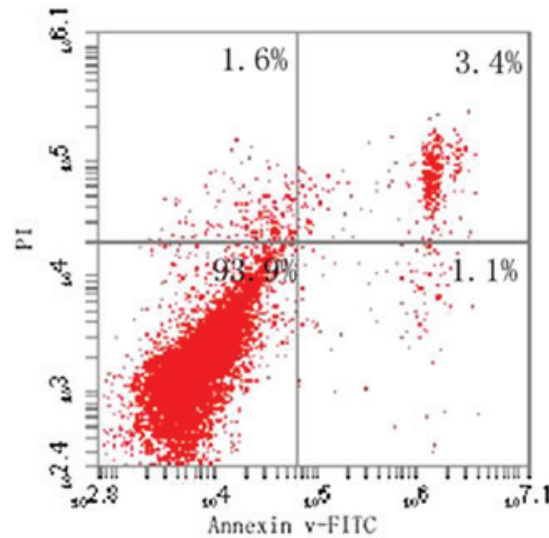

B

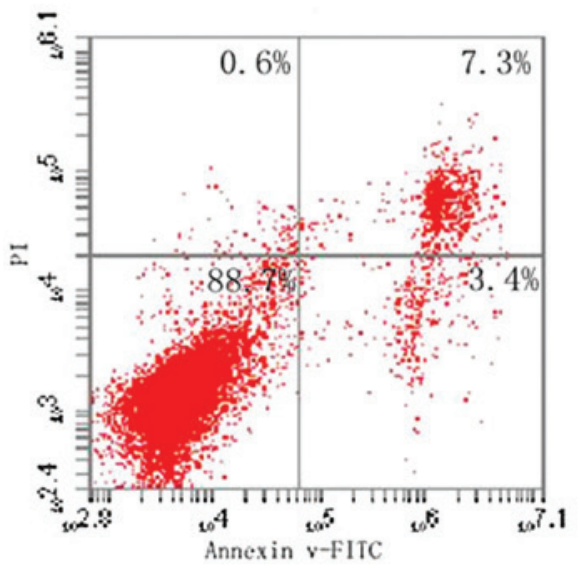

C

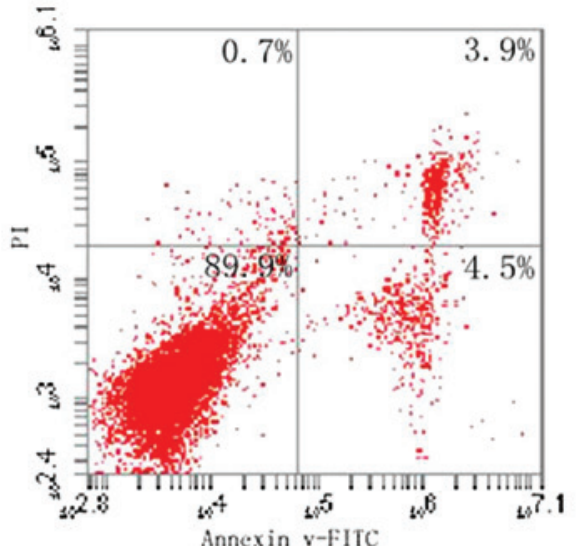

D

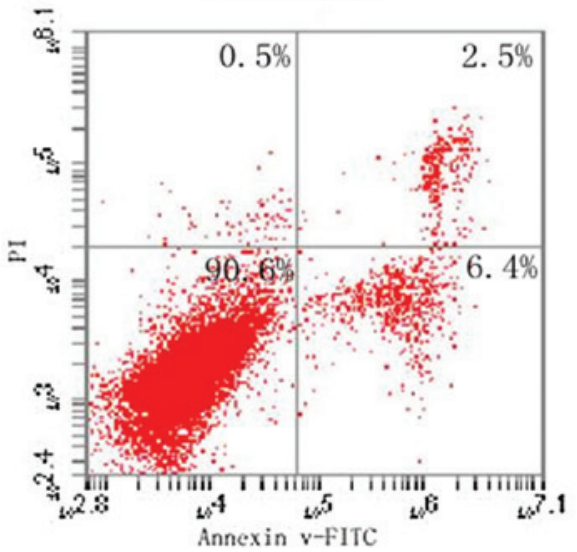

Figure 3. Flow cytometry was used to evaluate apoptosis in STC-1 cells following lipopolysaccharide (LPS) treatment. After starvation for $12 \mathrm{~h}$, cells were treated with different concentrations of LPS for a further $6 \mathrm{~h}$. The lower right quadrant shows the early apoptotic cells. Annexin V-fluorescein isothiocyanate (FITC) and propidium iodide (PI)-negative stained cells in the lower left quadrants are viable cells. The upper right quadrant shows the late apoptotic or necrotic cells. (A) Control group; (B) $0.5 \mu \mathrm{g} / \mathrm{ml}$ LPS; (C) $1 \mu \mathrm{g} / \mathrm{ml} \mathrm{LPS;} \mathrm{(D)} 10 \mu \mathrm{g} / \mathrm{ml}$ LPS.
A

$\operatorname{LPS}(\mu \mathrm{g} / \mathrm{ml})$

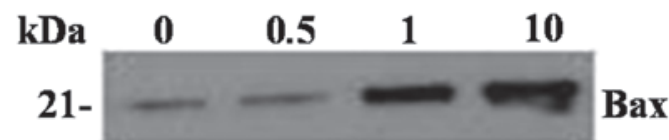

26-

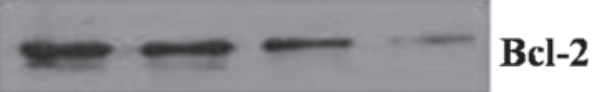

35-

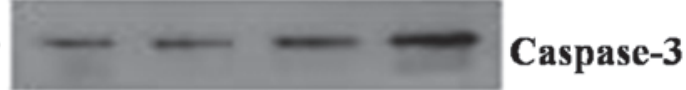

37-
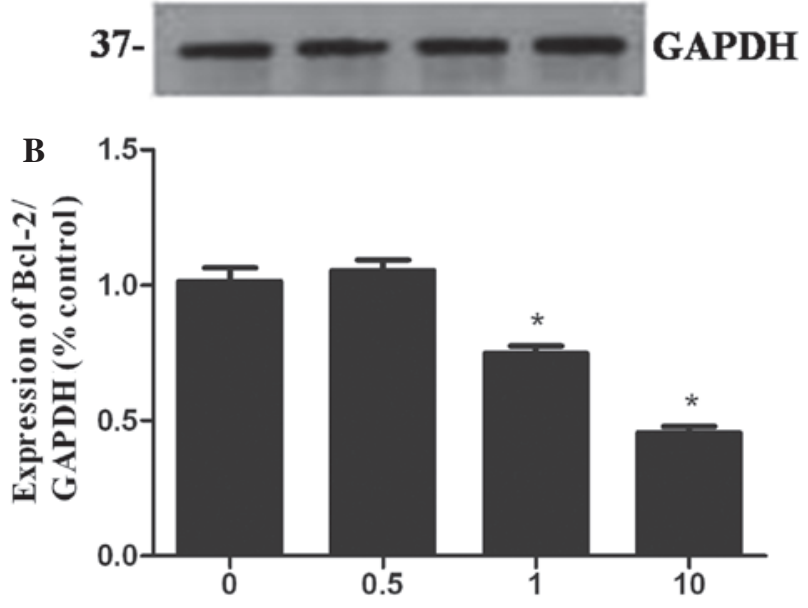

Concentration of LPS $(\mu \mathrm{g} / \mathrm{ml})$
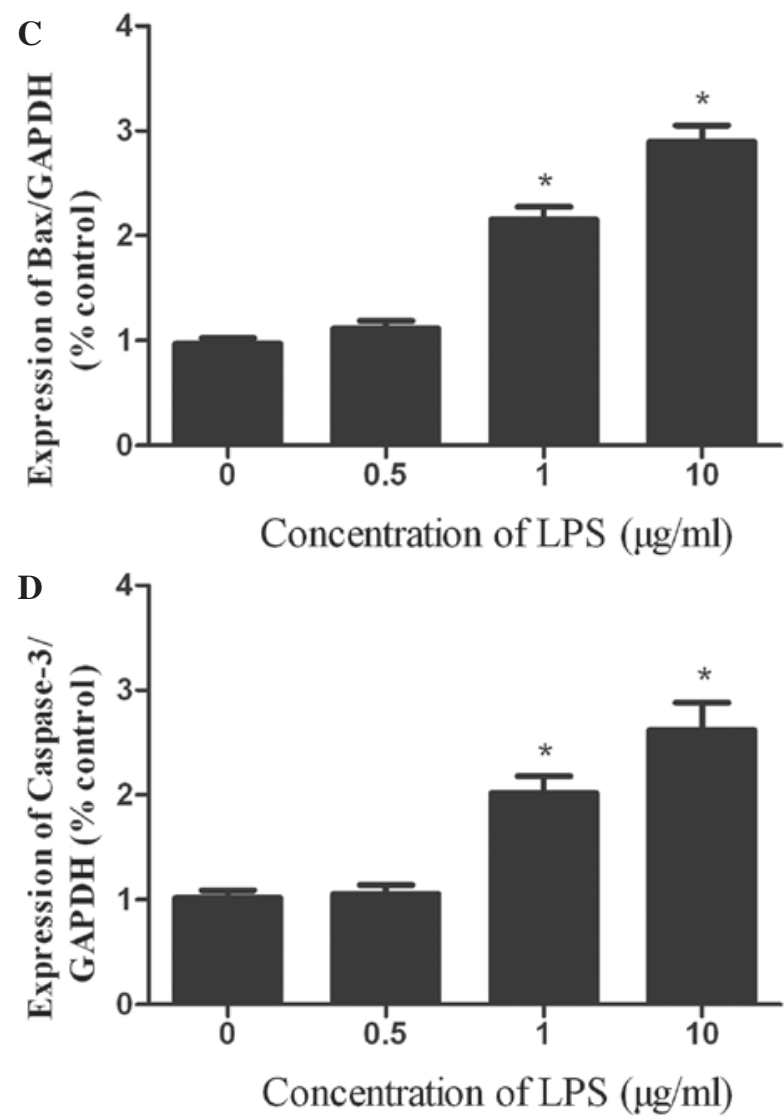

Figure 4. Effect of lipopolysaccharide (LPS) on Bax, Bcl-2 and caspase-3 expression in STC-1 cells. (A) After cells were treated with LPS (0, 0.5, 1 and $10 \mu \mathrm{g} / \mathrm{ml}$ ) for $24 \mathrm{~h}$, the expression of Bax, Bcl-2 and caspase- 3 proteins were detected by western blotting. (B-D) Densitometric analysis was used to determine the relative ratios of Bax, Bcl- 2 and caspase- 3 compared with the control. Asterisks $(\mathrm{P}<0.05)$ indicate significant differences compared with the control. GAPDH, glyceraldehyde 3-phosphate dehydrogenase. 
plot were not included in the calculations. The viable cells (annexin V-FITC- and PI-negative) are shown in the lower left quadrant. As shown in Fig. 3, there was a trend of increased apoptosis in the 1 and $10 \mu \mathrm{g} / \mathrm{ml}$ groups compared with the control groups (up to 4.5 and $6.4 \%$, respectively; $\mathrm{P}<0.05$ ). However, no significant difference was observed between the $0.5 \mu \mathrm{g} / \mathrm{ml}$ LPS group and the control group.

Effect of LPS on the expression of caspase-3, Bcl-2 and Bax proteins. As measured by western blotting (Fig. 4), incubation with LPS $(0.5,1$ and $10 \mu \mathrm{g} / \mathrm{ml})$ for $24 \mathrm{~h}$ markedly reduced the expression of $\mathrm{Bcl}-2$ protein, to 75 and $45 \%$ (compared with the controls) in the 1 and $10 \mu \mathrm{g} / \mathrm{ml}$ LPS groups, respectively. The increased expression level of Bax protein paralleled the decrease in the expression level of Bcl-2 protein. However, Bax protein expression increased 2.2 and 3.0 times in STC-1 cells following treatment with 1 and $10 \mu \mathrm{g} / \mathrm{ml}$ LPS, respectively (controls are set as 100\%). Furthermore, higher concentrations of LPS led to the increased cleavage of caspase-3. The levels of caspase-3 increased 2.0 and 2.6 times following treatment with 1 and $10 \mu \mathrm{g} / \mathrm{ml}$ of LPS, respectively. There were no significant changes in the expression of any of the three proteins in the $0.5 \mu \mathrm{g} / \mathrm{ml}$ LPS group.

\section{Discussion}

The growing epidemics of obesity and type 2 diabetes have led the scientific community to identify and develop new therapeutic targets. Over the past few years, the modulation of the secretory functions of enteroendocrine $\mathrm{L}$ cells has been the focus of research due to the powerful anti-diabetic activities of GLP-1. However, studies on the apoptosis of intestinal endocrine L cells remain limited. The secretion of GLP-1 has been shown to be markedly reduced in type 2 diabetes. Therefore, we hypothesized that this incretin defect may be related to the increased apoptosis of enteroendocrine L cells. A series of studies have shown that LPS may induce apoptosis in various cell types, such as fibroblasts, macrophages and endothelial cells (11-13). However, whether LPS is capable of inducing the apoptosis of enteroendocrine $\mathrm{L}$ cells has not been confirmed.

The results of this study demonstrated that LPS was capable of inhibiting the growth of STC-1 cells in a concentrationdependent manner. Cell viability, as determined by MTT assay, decreased with an increase in the concentration of LPS. Typical apoptotic features, such as cytoplasmic shrinkage, nuclear chromatin condensation and apoptotic bodies, were observed in STC-1 cells treated with 1 or $10 \mu \mathrm{g} / \mathrm{ml}$ LPS using Hoechst 33258.

Phosphatidylserine (PS) is located on the cytoplasmic surface of normal living cell membranes. Following apoptosis, PS is translocated from the inner plasma membrane to the outer plasma membrane and faces the extracellular environment. Annexin V has a high affinity for PS; therefore, fluorophorelabeled annexin V may be used to identify apoptotic cells. Our study revealed that the number of green cells, namely the apoptotic cells, increased with the increasing concentration of LPS. Flow cytometry data provide further evidence for this increase in apoptosis. This is consistent with the findings demonstrated by Hamada et al (14), in which LPS induced a dose-dependent increase in the number of TUNEL-positive hepatocytes.
Apoptosis, or programmed cell death, is an essential physiological process in which cells that are no longer required or are injured are eliminated (15). The best-studied mechanisms of apoptosis regulation involve members of the Bcl-2 family (16-18). A minimum of $15 \mathrm{Bcl}-2$ proteins have been identified, and they may be divided into proapoptotic proteins, such as Bax, Bak, Bad, Bcl-xs, Bid, Bik, Bim and Hrk, and antiapoptotic proteins, such as Bcl-2, Bcl-xl, Bcl-w, Bfl-1 and Mcl-1 (19). The balance between proapoptotic and antiapoptotic Bcl-2 family proteins determines whether a cell lives or dies. Therefore, the ratio of $\mathrm{Bcl}-2 / \mathrm{Bax}$ is of greater importance in determining the apoptosis of cells following apoptotic stimulation than the quantity of Bcl-2 alone (18). In this study, we found that the level of $\mathrm{Bcl}-2$ protein decreased, whereas the levels of Bax increased in STC-1 cells following exposure to LPS. The low ratio of Bcl-2/Bax in STC-1 cells may explain the high apoptotic rate of LPS-treated STC-1 cells. Furthermore, caspase family members play vital roles in apoptosis. Most notably, caspase- 3 is activated in apoptotic cells by the extrinsic (death ligand) and intrinsic (mitochondrial) pathways $(20,21)$. As an executioner caspase, the caspase-3 zymogen has virtually no activity until it is cleaved by initiator caspases after apoptotic signaling events have occurred (22). Once caspase-3 is activated, apoptosis proceeds and cannot be reversed. Our results showed that the level of cleaved caspase- 3 increased after STC-1 cells had been exposed to LPS for $24 \mathrm{~h}$, which indicated that LPS induced apoptosis in STC-1 cells. This was consistent with the results of Deaciuc et al (23), who showed that liver ECs, derived from mice who had been intravenously administered LPS, had enhanced caspase-3 activity.

Modulation of the composition of the intestinal flora may become an effective treatment strategy for type 2 diabetes. New approaches for the therapeutic exploitation of the microbiota, such as probiotics and prebiotics, may be capable of changing the balance of gut inhabitants, which might then be used to treat intestinal inflammatory disorders, metabolic syndromes and systemic immune conditions (24). Reducing the concentration of LPS by decreasing the number of Bacteroidetes in the gut may inhibit the apoptosis of enteroendocrine L cells and increase GLP-1 excretion in type 2 diabetes.

In conclusion, we have demonstrated that LPS induces apoptosis in STC-1 cells by decreasing the expression of Bcl-2/Bax protein and increasing caspase-3 activities. Enteroendocrine L cell apoptosis may correlate with a decrease in GLP-1 secretion in type 2 diabetes.

\section{References}

1. Larsen N, Vogensen FK, van den Berg FW, et al: Gut microbiota in human adults with type 2 diabetes differs from non-diabetic adults. PLoS One 5: e9085, 2010.

2. Drucker DJ and Nauck MA: The incretin system: glucagon-like peptide- 1 receptor agonists and dipeptidyl peptidase- 4 inhibitors in type 2 diabetes. Lancet 368: 1696-1705, 2006.

3. Toft-Nielsen MB, Damholt MB, Madsbad S, et al: Determinants of the impaired secretion of glucagon-like peptide-1 in type 2 diabetic patients. J Clin Endocrinol Metab 86: 3717-3723, 2001.

4. Vilsboll T, Krarup T, Deacon CF, Madsbad S and Holst JJ: Reduced postprandial concentrations of intact biologically active glucagon-like peptide 1 in type 2 diabetic patients. Diabetes 50: 609-613, 2001.

5. Cani PD and Delzenne NM: Gut microflora as a target for energy and metabolic homeostasis. Curr Opin Clin Nutr Metab Care 10: 729-734, 2007. 
6. CreelySJ,McTernanPG,KusminskiCM,etal:Lipopolysaccharide activates an innate immune system response in human adipose tissue in obesity and type 2 diabetes. Am J Physiol Endocrinol Metab 292: E740-E747, 2007.

7. Lü F, Jin T and Drucker DJ: Proglucagon gene expression is induced by gastrin-releasing peptide in a mouse enteroendocrine cell line. Endocrinology 137: 3710-3716, 1996.

8. Jin $\mathrm{T}$ and Drucker DJ: The proglucagon gene upstream enhancer contains positive and negative domains important for tissue-specific proglucagon gene transcription. Mol Endocrinol 9: 1306-1320, 1995.

9. Abello J, Ye F, Bosshard A, Bernard C, Cuber JC and Chayvialle JA: Stimulation of glucagon-like peptide-1 secretion by muscarinic agonist in a murine intestinal endocrine cell line. Endocrinology 134: 2011-2017, 1994.

10. Stoscheck CM: Quantitation of protein. Methods Enzymol 182: 50-68, 1990.

11. Alikhani M, Alikhani Z, He H, Liu R, Popek BI and Graves DT: Lipopolysaccharides indirectly stimulate apoptosis and global induction of apoptotic genes in fibroblasts. J Biol Chem 278 : 52901-52908, 2003

12. Xaus J, Comalada M, Valledor AF, et al: LPS induces apoptosis in macrophages mostly through the autocrine production of TNF-alpha. Blood 95: 3823-3831, 2000.

13. Hull C, McLean G, Wong F, Duriez PJ and Karsan A: Lipopolysaccharide signals an endothelial apoptosis pathway through TNF receptor-associated factor 6-mediated activation of c-Jun NH2-terminal kinase. J Immunol 169: 2611-2618, 2002.

14. Hamada E, Nishida T, Uchiyama Y, et al: Activation of Kupffer cells and caspase- 3 involved in rat hepatocyte apoptosis induced by endotoxin. J Hepatol 30: 807-818, 1999.
15. Peter ME: Programmed cell death: Apoptosis meets necrosis. Nature 471: 310-312, 2011.

16. Bannerman DD and Goldblum SE: Mechanisms of bacterial lipopolysaccharide-induced endothelial apoptosis. Am J Physiol Lung Cell Mol Physiol 284: L899-L914, 2003.

17. Huang YY, Peng CH, Yang YP, et al: Desipramine activated Bcl-2 expression and inhibited lipopolysaccharide-induced apoptosis in hippocampus-derived adult neural stem cells. J Pharmacol Sci 104: 61-72, 2007.

18. Youle RJ and Strasser A: The BCL-2 protein family: opposing activities that mediate cell death. Nat Rev Mol Cell Biol 9: 47-59, 2008.

19. Tamm I, Schriever F and Dörken B: Apoptosis: implications of basic research for clinical oncology. Lancet Oncol 2: 33-42, 2001.

20. Salvesen GS: Caspases: opening the boxes and interpreting the arrows. Cell Death Differ 9: 3-5, 2002.

21. Ghavami S, Hashemi M, Ande SR, et al: Apoptosis and cancer: mutations within caspase genes. J Med Genet 46: 497-510, 2009

22. Walters J, Pop C, Scott FL, et al: A constitutively active and uninhibitable caspase-3 zymogen efficiently induces apoptosis. Biochem J 424: 335-345, 2009.

23. Deaciuc IV, Fortunato F, D'Souza NB, Hill DB, Schmidt J, Lee EY and McClain CJ: Modulation of caspase-3 activity and Fas ligand mRNA expression in rat liver cells in vivo by alcohol and lipopolysaccharide. Alcohol Clin Exp Res 23: 349-356, 1999.

24. Hord NG: Eukaryotic-microbiota crosstalk: potential mechanisms for health benefits of prebiotics and probiotics. Annu Rev Nutr 28: 215-231, 2008. 